\title{
KLAUS WyrtKi's Forty YeARs OF CONTRIBUTIONS TO OCEANOGRAPHY: His Students' Perspective
}

\author{
By Roger Lukas, William Patzert, Gary Meyers and William Emery
}

\begin{abstract}
Professor Klaus Wyrtki of the University of Hawaii was recently awarded the American Geophysical Union's prestigious Maurice Ewing medal for his many contributions to oceanography. He was also honored by his students and colleagues with a day-long special symposium that focused on the major themes of his forty years of research in physical oceanography. In this article, four of his Ph.D. students summarize his distinguished career and important contributions to our understanding of the oceanic circulation and its interaction with the overlying atmosphere.
\end{abstract}

TH of a seminar by Professor Klaus Wyrtki, in which he describes the process of his education as an oceanographer. Wyrtki's chronicle nicely illustrates his educational philosophy and its roots. The basic idea is that it is the student's responsibility to acquire an

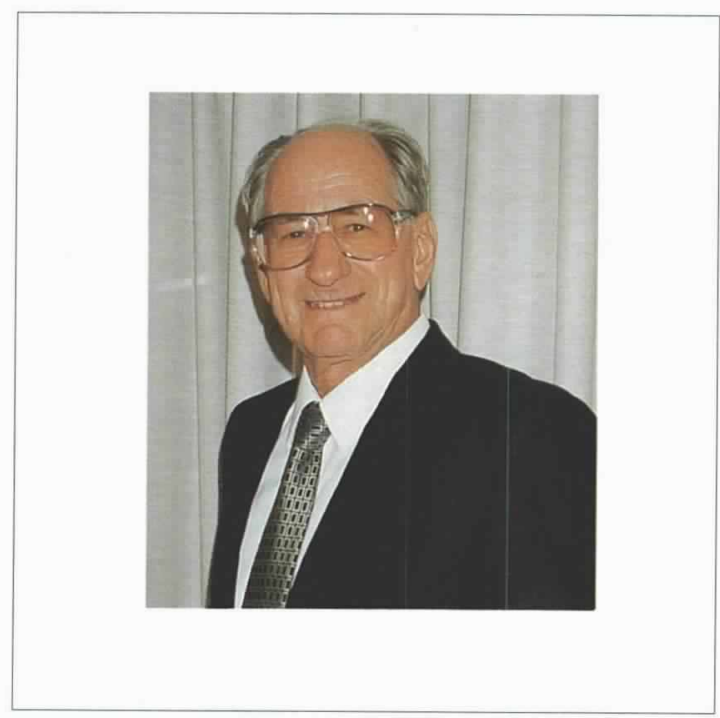

Professor Klaus Wyrtki was the honored recipient of the Maurice Ewing medal, awarded in December 1989 by the American Geophysical Union.

Roger Lukas, Joint Institute for Marine and Atmospheric Research, University of Hawaii, 1000 Pope Road, MSB 312, Honolulu, HI 96822; William Patzert, Jet Propulsion Laboratory, Mail Stop 300-323, 4800 Oak Grove Drive, Pasadena, CA 91109; Gary Meyers, CSIRO Division of Oceanography, GPO Box 1538, Hobart, Tasmania, 7001, Australia; William Emery, CCAR, University of Colorado, Box 431, Boulder, CO 80309. education, given the opportunities that are available. One has the sense from this seminar that he appreciates how much more difficult it is to be a student today, with such a large body of knowledge which must be assimilated in order to call oneself an oceanographer. On the other hand, there are many more mentors in the field of physical oceanography than when Wyrtki was a student. All of us agree that the notion of graduate education as an "apprenticeship" is one that we, as students under Wyrtki, have come to appreciate over the years. Here, we honor our major professor, Klaus Wyrtki, with our view of his career and his contributions.

After finishing his graduate education and a postdoctoral position with Prof. Gunter Dietrich in Kiel (read accompanying article for details), the young Wyrtki underwent a bold professional migration which took him from Indonesia (1954-57), to Australia (1958-61), to the Scripps Institution of Oceanography (1961-64), and finally to Hawaii (1964-present). Over a period of about ten years, Wyrtki accepted a series of positions which provided him with different opportunities to conduct important research on regional oceanography. During this period, he synthesized existing data sets (supplemented with his own observations) to provide an understanding of various pieces of the larger ocean puzzle. The success of this approach led him to later advise his students to "integrate, don't differentiate" the data, advice he later ignored in his pursuit of the understanding of the large-scale tropical Pacific "El Niño problem."

His first job was as the founder and Director (from 1954-57) of the Institute of Marine Research in Jakarta, Indonesia, where he concentrated on the oceanography of this region. The result was the still 
definitive and comprehensive synthesis, "Physical Oceanography of the Southeast Asian Waters," published in 1961. One of the most important and lasting conclusions of this study was the recognition that there is a net flow of water through the Southeast Asian waters from the Pacific to the Indian Ocean. Later estimates of throughflow were even larger than Wyrtki's estimates and this throughflow has recently been understood to have major implications for the general circulation of the oceans.

Next, while at the Commonwealth Scientific and Industrial Research Organization in Sydney, Australia, Wyrtki expanded the scope of his previous water mass analyses and studies of upper ocean processes to the eastern Indian and the western Pacific Oceans. Here, Wyrtki also initiated new research on the Antarctic Circumpolar Current and the associated convergences and divergences, which led others into more general studies of the role of the Southern Oceans in global thermohaline circulation.

Recruited by Roger Revelle in the early 1960s, Klaus then moved to the Scripps Institution of Oceanography. Sponsored by the Inter-American Tropical Tuna Commission, Wyrtki switched his interest to studies of the regional circulation of the eastern tropical Pacific Ocean. Again, he synthesized historical current and temperature observations to provide a lasting contribution to our knowledge of the ocean circulation of the eastern tropical Pacific. It was during this period that Wyrtki encountered the El Niñophenomenon and interacted with Jacob Bjerknes, who had just developed the hypothesis suggesting that El Niño was controlled by feedbacks between the atmosphere and ocean over the entire tropical Pacific. However, it wasn't until nearly a decade later that Wyrtki was to return to this most challenging problem.

In 1964, Wyrtki was recruited by George Woollard, Director of the newly-formed Hawaii Institute of Geophysics (HIG), to help build a Department of Oceanography at the University of Hawaii. Initially, this new institute focused on the Hawaiian regional oceanography, and Professor Wyrtki led a group of students (including Bill Patzert and Bill Emery) in making pioneering measurements throughout the Hawaiian Archipelago. Today, the syntheses of these observations remain as the definitive description of Hawaiian waters' physical oceanography. Each reprinting of his HIG technical reports from that era "sells out" almost instantly.

At the same time that the studies of the Hawaiian waters was under way, Wyrtki's research expanded in scope to include large-scale studies of the entire North Pacific Ocean as well as the Indian Ocean. The data collection phase of the International Indian Ocean Expedition had been completed in the mid1960s and over the following five years Wyrtki and his student, Edward Bennett, produced the outstanding Indian Ocean Atlas. This mammoth job in retrospective data analysis was something that only someone with Klaus' feel for data could have done.

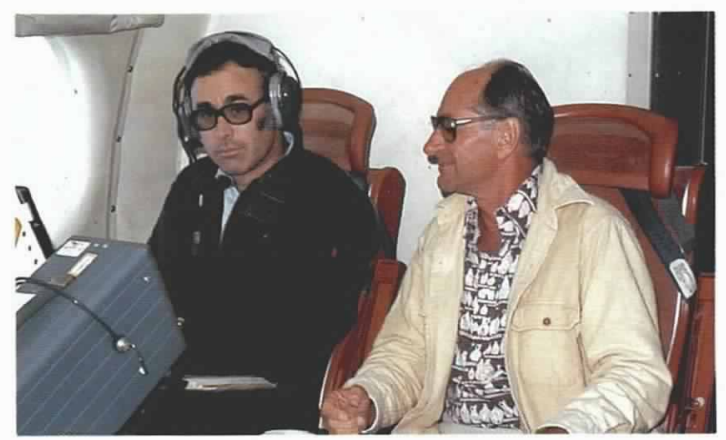

Klaus Wyrtki (r) and Tim Barnett enjoying the view from a NOAA P-3 aircraft during the Hawaii-Tahiti Shuttle Experiment.

Today, twenty years later, this Atlas embodies most of our knowledge of the hydrography of that ocean.

Nineteen-seventy began the International Decade of Ocean Exploration (IDOE), and Wyrtki's earlier work on the heat budget of the North Pacific Ocean involved him in the leadership of the NSF- and ONRfunded North Pacific Experiment (NORPAX). This pioneering program was the first organized attempt to study and understand the role of the upper ocean in interannual climate variability, and it was organized into a midlatitude component and a tropical component. Wyrtki took the lead in the development of the tropical component, conducting a series of studies into the dynamics and thermodynamics of the tropical Pacific. Two of us (Gary Meyers and Roger Lukas) studied under Wyrtki during this period; we were fortunate to be involved in this early stimulating and productive period of systematic research in Pacific tropical air-sea interaction.

(It is important to point out that Klaus really anticipated the importance of global climate research and the role of the ocean. At this time the air-sea interaction business was very small scale and process oriented. Nobody could conceive of global interactions as approachable and therefore neglected them. Klaus knew of the importance of large-scale studies and, unfettered by worries about statistical significance, he insisted that we look at the data to find the relationships that must be there.)

One of the major tasks that Wyrtki undertook in NORPAX was to build the Pacific Island Sea Level network on the remnants of the tide gauge installations that had been poorly maintained by the National Oceanic and Atmospheric Administration. Early in the planning days for NORPAX new ideas were being discussed, and Klaus, along with Ray Montgomery, believed that long term sea level changes could be used to say something about the changes in ocean circulation. There was considerable resistance to this claim and only the Wyrtki persistence established the network and demonstrated the validity of the approach. Two of us (Gary Meyers and Bill Emery) put in the first of the new sea level stations. Even after the relatively "easy" funding climate of the IDOE was over, Wyrtki tenaciously continued to "lovingly" tend the existing stations and expand the network.
K anticipated the importance of global climate research and the role of the ocean. 


\section{This was not material}

you could learn in a

book or even in a

class.
Today, the Tropical Ocean/Global Atmosphere (TOGA) Indo-Pacific Sea Level Network, including fifty-one tide gauge stations (thirty-four of which report in near-real-time via satellite), continues to be internationally recognized as one of the major components of the global ocean monitoring system.

The simultaneous analysis of the historical sea level data, as well as surface wind data sets. lead Klaus to develop fundamentally new hypotheses about the cause and effect of the El Niño phenomenon (see his pioneering study "Equatorial Currents in the Pacific 1950 to 1970 and their relations to the trade winds," Wyrtki, 1974) which resulted in his seminal paper, "El Niño-the Dynamic Response of the equatorial Pacific Ocean to atmospheric forcing" (Wyrtki, 1975). In these important papers, we see that Klaus' "integral" descriptions of large-scale processes have also been "differentiated" with the intent of understanding the time evolution of the El Niño events.

These hypotheses lead to bold attempts at predicting and nonpredicting El Niño occurrences in 1975 and 1982, respectively. Two of us, Bill Patzert and Roger Lukas, spent several months at sea searching for the elusive, "aborted" 1975 El Niño-a character-building experience for all involved! Although these predictions were not exactly rewarded with success, they stimulated considerable discussion and invigorated new studies. Spurred on by this clear evidence of incomplete understanding. Wyrtki extended his hypotheses in his paper, "Water Displacements in the Pacific and the Genesis of El Niño Cycles" (Wyrtki, 1985). Returning to the integral approach, he was able to show from sea level data that the El Niño was preceded by an anomalous accumulation of warm, upper-layer waters in the tropical Pacific, and that these events result in a net poleward export of warm water from the tropics.

Using the results of these studies, Klaus resurrected an idea suggested by Ray Montgomery in the early 1970s and organized the 16-month-long Hawaii-Tahiti Shuttle Experiment, which took place during 1979-80. This was the last major thrust of NORPAX and provided the first, consistent description of the seasonal variations of the tropical currents and water masses of the central Pacific. These observations are a benchmark against which year-to-year variations of the central equatorial Pacific Ocean can be measured, and they continue to provide an important testbed for future theoretical and modeling efforts. This experiment also provided a test of, and a consistent framework for, the use of sea level measurements as a tool for monitoring the tropical Pacific Ocean circulation and upper ocean heat content.

The prodigy of the NORPAX tropical program, the international TOGA research program. continues to build and expand on the ideas of Bjerknes, Wyrtki and Gill. among others. This decade-long program is nearing its midpoint, and the observations have verified the hypotheses that explain the coupled oceanatmosphere system put forward by Wyrtki. Looking back through Wyrtki's work, we can see an observa- tional philosophy that emphasizes the combined strength of different observing systems, which has been the fundamental tenet of the TOGA program. Wyrtki's sea level network has been an important component of the TOGA ocean observing system, and it also has provided important in situ verification and calibration data for the remote sensing of sea level variability using the Geosat spaceborne altimeter.

Klaus Wyrtki is an oceanographer in the classical interdisciplinary sense: providing the "grand synthesis" wherever possible. making pioneering new observations where data limitations are too great, and approaching his research with an understanding of meteorology and other disciplines. His work is respected and used by meteorologists, geochemists, biologists and many others. Through four decades. these contributions have spanned a variety of regions and included many processes. During this very productive period. Wyrtki has unselfishly shared his ideas and data with his students and colleagues. His insight, intuition and considerable energy in the pursuit of understanding of the ocean circulation and its role in interannual climate variability is internationally recognized and respected.

This summary of Klaus' career would be incomplete if we did not mention Wyrtki. the man. His experience, guidance and "common sense" not only makes him a very effective researcher and leader among his peers, but also an outstanding teacher. His tremendous capability to retain detailed information about data and what they mean has been Klaus' key to success. It is something that is almost impossible to teach to others and it is the essence of why the "apprentice" model was so important to those of us that studied with him. This was not material you could learn in a book or even in a class. Only by working with him and interacting with him could you gain an appreciation of this skill and its importance. Graduate school was both a scientifically exciting time and just plain fun. Along the way, Klaus opened up many opportunities for us, his students, and we are very grateful. Klaus, mahalo (thank you), smooth sailing, and we look forward to continued collaborations in future years. Aloha nui loa!

\section{References}

Wyrtki, K., 1961: Physical Oceanography of the Southeast Asian Waters. University of California, NAGA Rept. No. 2. 195 pp.

Wyrtki. K., 1971: Oceanographic Atlas of the International Indian Ocean Expedition. National Science Foundation, Washington. D.C.. $531 \mathrm{pp}$.

Wyrtki, K. 1974: Equatorial currents in the Pacific 1950 to 1970 and their relations to the trade winds. J. Phys.Oceanogr. 4. 372-380.

Wyrtki.K... 1975: El Niño-The dynamic response of the equatorial Pacific Ocean to atmospheric forcing. J. Phys. Oc eanogr., 5. 572-584.

Wyrtki. K.. 1985: Water displacements in the Pacific and the genesis of El Niño cycles.J. Geophys. Res., 90(C+).712971.32. ב 